\title{
'Dagan' Pear
}

\section{Doron Holland, Mordechai Dagan, ${ }^{1}$ Irit Bar-Yaakov, and Kamel Hatib Section of FruitTree Breeding and Genetics, Agricultural Research Organization, Newe Ya'ar Research Center, P.O. Box 1021, Ramat Yishay, 30095, Israel}

\section{Additional index words. Pyrus communis, cultivar, hot climate}

The availability of high-quality pear cultivars in Israel is very limited due to inadequate climate conditions. Another major problem is a lack of an appropriate rootstock for the selected cultivars in these hot climate conditions (Assaf et al., 1972; Gur et al., 1978). The result is that the pear industry in Israel is based mainly on three cultivars that were introduced from abroad-'Spadona Estiva', 'Coscia', and 'Gentile Bianca'. The Italian cultivar 'Spadona Estiva' (www.fruttantica. it) is the most common pear grown in Israel (about 80\%). 'Dagan' pear (Pyrus communis L.) is a new Israeli pear cultivar with a good flavor and an improved size and appearance compared to 'Spadona Estiva'. It is intended for consumption after storage. The tree is productive with a consistent bearing of regular shape, medium size fruit. It performs well on Pyrus betulaefolia Bunge rootstock. This rootstock was found to be an appropriate rootstock for growing several pear cultivars in the hot Israeli climate conditions (Assaf et al., 1972). The above-mentioned qualities of 'Dagan' pear make it a suitable cultivar for commercial growth in hot climates.

\section{Origin}

'Dagan' is the result of a cross made in 1973 between 'Spadona Estiva' and an unknown European pear. It was first selected by Raphael Assaf (unpublished data) in 1980, in the Agricultural Research Organization, Newe Ya' ar Research Center and tested as 'Agas 2'. Scions from the selected plant were grafted on $P$. betulaefolia seedlings and planted in the pear orchard in Newe Ya' ar Research Center in 1981. Newe Ya'ar is located in the western Yizre'el Valley, lat. $32^{\circ} 42^{\prime} \mathrm{N}$, long. $35^{\circ} 11^{\prime} \mathrm{E}$. The mean diurnal minimum temperature in January is 6 ${ }^{\circ} \mathrm{C}$. The mean diurnal maximum temperature in July is $33^{\circ} \mathrm{C}$. The average annual amount of chilling hours (below $8^{\circ} \mathrm{C}$ ) is 445 . Since 1981 a detailed follow-up is being done on the tree and the fruit characteristics. In March 2001 the cultivar was applied for registration in Israel (application number 3262/01).

\section{Description}

Tree traits. 'Dagan' trees are moderately vigorous and are columnar in habit when grafted on P. betulaefolia rootstocks. The leaves are elliptic and glabrous with a rounded base

Received for publication 19 Jan. 2004. Accepted for publication 22 Feb. 2004.

${ }^{1}$ Horticulture research technician (retired). and an acute tip. The blade margins are finely serrate. The petiole is long. Flowers have white petals and the anthers are pink to violet. It is susceptible to fire blight (Erwinia amylovora (Burr.) Winslow et al.).

Tree productivity. The tree performs well on $P$. betulaefolia rootstock under the conditions of the Israeli hot climate. It produces regular yields when provided with the appropriate pollinizers (Table 1). Since 'Dagan' has not yet been grown in commercial or semi-commercial orchards, fruit yield is hard to estimate. Based on the evaluation of two trees, the average yield in 3 years is about $30 \mathrm{t} \cdot \mathrm{ha}^{-1}$.

Tree bloom and pollination. Flowering in Newe Ya' ar Research Center occurs from early March to beginning of April and coincides well with that of 'Coscia', 'Spadona Estiva', 'Gentile Bianca' and 'Lawson'. These pears are considered as early flowering when compared to European pears such as 'Bartlett'. 'Dagan' is self-incompatible. In controlled pollination tests stigma surfaces of emasculated 'Dagan' flowers were hand pollinated by pollen from known cultivars. Fruit set was used to determine compatibility. Pollination tests were done two years successively on 12 and 13 year old trees. The results indicate that the pear cultivars

Table 1. Fruit set of 'Dagan' pear following controlled pollination tests.

\begin{tabular}{lc}
\hline Pollen source & Fruit set $(\%)$ \\
\hline Dagan & $0.0 \pm 0.0$ \\
Spadona Estiva & 23.4 \\
Coscia & $28.0 \pm 6.4$ \\
Lawson & $16.8 \pm 3.2$ \\
\hline
\end{tabular}

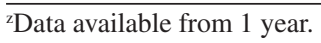

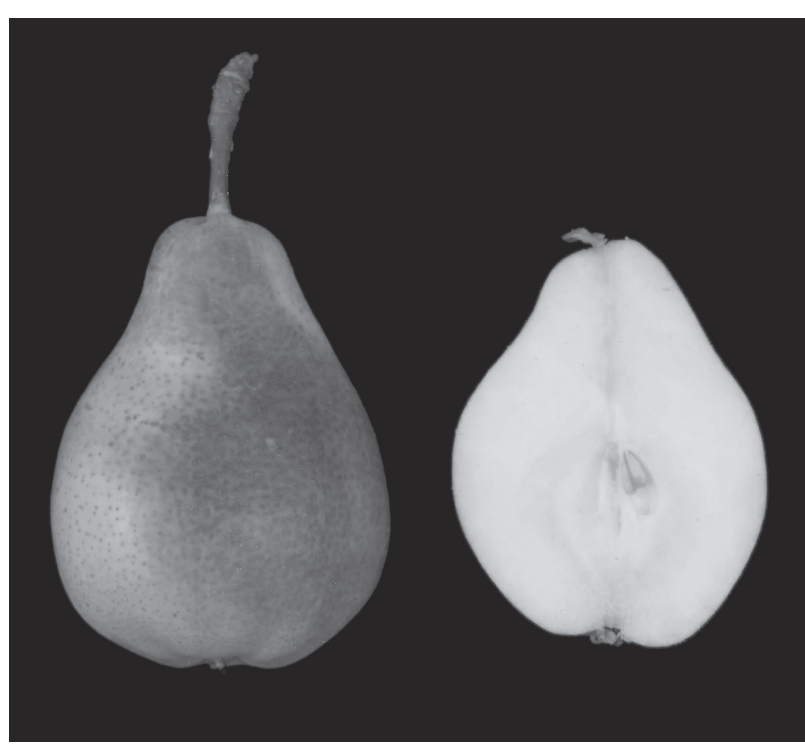

'Spadona Estiva', 'Lawson', and 'Coscia' could serve as pollinizers in similar degrees of efficiency (Table 1). However, none of them is fully compatible, therefore, two pollinizers are recommended.

Fruit traits. The 'Dagan' fruit is symmetrical and pyriform in shape. The average fruit diameter is $64.6 \pm 1.4 \mathrm{~mm}$, the average fruit length is $82 \mathrm{~mm}$ and the average weight is $162 \mathrm{~g}$. under growth conditions in Newe Ya'ar Research Center. The fruit tastes sweet and ripened fruit total soluble solids is $12.5 \%$ to $13.0 \%$. The flesh texture is pleasant, melting and juicy when fully ripened. When freshly harvested, fruit has slight astringency. The flesh color is white. The skin is smooth, free of russeting. When picked, the skin is green (RHS 123B), turning bright green to yellow as the fruit ripens, and there is up to $50 \%$ pink to red blush (RHS 59B), as shown in Fig.1.

Fruit maturity. Under Newe Ya'ar growth conditions the fruit ripens on the tree at midAugust. However, commercial fruit harvest is done at the end of July-beginning of August as compared to mid-August for 'Bartlett'. A selective harvest is required. Preliminary data indicate that the fruit are preserved well under standard storage conditions. However for best quality and for removal of astringency it has to be kept in cold storage for about 2 months before marketing. The fruit is also acceptable for consumption without any storage.

\section{Availability}

'Dagan' was released for commercial usage in Israel in 2002. Limited quantities of nonindexed budwood are available from Newe Ya'ar Research Center upon written request. The cultivar was applied for registration under the terms of the Israeli Plant Breeders' Right Law 5733-1973.

\section{Literature Cited}

Assaf, R., P. Speigel-Roy, and D. Barak. 1972. Problems of the pear acclimatization in warm countries choice of varieties, rootstocks (in French). Compte Rendu du Symposium Culture du Poirier, Station de Recherches d'Angers, France.

Fruttantica. Recupero e valorizzazione di variete locali di "Frutta Antica"-Pere. 18 June 2003. < http://www.fruttantica. it $/$ pere $/ \mathrm{htm}>$

Gur, A., D. Zamet, and E. Arad. 1978. A pear rootstock trial in Israel. Scientia Hort. 8:249-264.

R.H.S. Color Chart. 1966. The Royal Horticultural Society, London. 